\title{
Interaction of body mass index and hemoglobin concentration on blood pressure among pregnant women in Guangxi, China
}

\author{
Qiuan Zhong ${ }^{1 \dagger}$, Jiangyan $\mathrm{Xu}^{2+}$, Yingquan Long ${ }^{3}$, Yingying Deng ${ }^{1}$, Jinlan $\mathrm{Hu}^{1}$, Xiaofei $\mathrm{Li}^{1}$ and Xiaogiang Qiu ${ }^{{ }^{*}}$
}

\begin{abstract}
Background: Body mass index (BMI) and hemoglobin $(\mathrm{Hb})$ are positively associated with hypertensive disorders among pregnant women. The aim of this study was to estimate a potential interaction between high BMl and high $\mathrm{Hb}$ concentrations on systolic blood pressure (SBP) and diastolic blood pressure (DBP) in pregnancy.

Methods: We recruited 4497 single-birth women aged 18-43 years who received routine antenatal care at three hospitals of Guigang, Guangxi, China, from December 2007 to January 2011. Of 4497 participants, 3472 women were in the first trimester, with following up, 2986 women and 2261 women were left in the second and third trimester, respectively. Clinical data were derived from medical records of each woman. We used multivariable linear regression, by trimesters of pregnancy, to evaluate the associations of high $\mathrm{BMI}$ and high $\mathrm{Hb}$ concentrations with SBP and DBP according to cross-sectional design.

Results: In multivariable analyses, BMI was positively associated with SBP throughout all trimesters, but the corresponding association for $\mathrm{Hb}$ concentrations only in the first trimester, whereas both $\mathrm{BMI}$ and $\mathrm{Hb}$ concentrations were positively associated with DBP in the first and third trimesters. After full adjustment for confounding, the average differences in SBP and DBP comparing women with high BMl and high $\mathrm{Hb}$ to those with non-high $\mathrm{BMl}$ and non-high $\mathrm{Hb}$ were $2.9 \mathrm{mmHg}(95 \% \mathrm{Cl}: 0.8$ to $5.0 \mathrm{mmHg})$ and $3.9 \mathrm{mmHg}(95 \% \mathrm{Cl}: 1.5$ to $6.3 \mathrm{mmHg})$ in the first trimester, $2.6 \mathrm{mmHg}$ ( $95 \% \mathrm{Cl}: 0.4$ to $4.8 \mathrm{mmHg}$ ) and $1.5 \mathrm{mmHg}(95 \% \mathrm{Cl}:-1.3$ to $4.3 \mathrm{mmHg}$ ) in the second trimester, and $4.8 \mathrm{mmHg}(95 \% \mathrm{Cl}$ : 2.3 to $7.4 \mathrm{mmHg}$ ) and $5.7 \mathrm{mmHg}(95 \% \mathrm{Cl}: 3.2$ to $8.3 \mathrm{mmHg}$ ) in the third trimester, respectively. With respect to the interaction, significant combined effects between high BMl and high $\mathrm{Hb}$ were confirmed on SBP $(P=0.02)$ and DBP $(P=0.004)$ in the third trimester, and the amount of interaction on SBP and DBP were $2.0 \mathrm{mmHg}$ ( $95 \% \mathrm{Cl}: 0.1$ to $3.9 \mathrm{mmHg}$ ) and $2.3 \mathrm{mmHg}(95 \% \mathrm{Cl}: 0.4$ to $4.3 \mathrm{mmHg}$ ), respectively.
\end{abstract}

Conclusion: Our findings suggest that high BMl and high $\mathrm{Hb}$ concentrations may have a synergistic effect on blood pressure in late stage of pregnancy.

Keywords: Body mass index, Hemoglobin, Blood pressure, Interaction, Pregnancy

\section{Background}

High blood pressure during pregnancy contributes to the risks of not only adverse neonatal outcomes but also maternal deaths $[1,2]$. Although the etiology of hypertensive disorders during pregnancy is not yet completely clear, maternal anthropometric measure such as high body mass index (BMI) in pregnancy has been reported to

\footnotetext{
*Correspondence: xqqiu9999@sina.com

${ }^{\dagger}$ Equal contributors

'Department of Epidemiology, Guangxi Medical University School of Public Health, 22 Shuangyong Road, Nanning, Guangxi 530021, China

Full list of author information is available at the end of the article
}

increase the risk of pregnancy-induced hypertension (PIH) or preeclampsia [3-6]. Similarly, several studies have shown that maternal hemoglobin $(\mathrm{Hb})$ levels were positively associated with PIH [7-9]. Moreover, a review suggests that higher than normal hemoglobin concentrations should be regarded as an indicator of possible pregnancy complications [10]. Some of the above findings [4,5,7], however, may be limited because of small sample size or insufficient gestational weeks.

The mechanisms underlying the positive association of $\mathrm{Hb}$ levels with pregnancy blood pressure are incompletely

\section{Biomed Central}


understood, but previous evidences suggested that elevated $\mathrm{Hb}$ levels might impact hypertensive disorders in pregnant $[7,10,11]$ as well as non-pregnant women [12] via hemoconcentration or increased blood viscosity, which is generally associated with both overall adiposity and abdominal adiposity [13]. Further, a population-based study, particularly on the association between $\mathrm{Hb}$ levels and BMI during pregnancy, showed that $\mathrm{Hb}$ levels were significantly associated with BMI in 561 pregnant women [14]. However, less is known about the combined effect of BMI and $\mathrm{Hb}$ levels on blood pressure in pregnancy. Thus, in this large sample study, we further evaluated the potential interaction between high BMI and high $\mathrm{Hb}$ concentrations on systolic blood pressure (SBP) and diastolic blood pressure (DBP) in all trimesters of pregnancy.

\section{Methods}

\section{Study population}

First, we categorized all hospitals that can provide a routine antenatal care into three stratifications including primary, secondary, and tertiary hospitals in Guigang, Guangxi Zhuang Autonomous Region, China, then randomly selected one hospital from each stratification using cluster sampling. The present study was embedded in the antenatal care at three hospitals during December 2007 to January 2011. A total of 5701 healthy women aged $\geq 18$ years with singleton pregnancies who attended their the first antenatal care at gestational weeks 10 to 16 were accumulatively enrolled, we excluded 41 in vitro fertilization and 1163 with incomplete data. Finally, 4497 eligible women aged 18-43 years were left to follow up with the routine antenatal visits. Gestational age was based on the first day of the last menstrual period, for 1169 women (26\%) with neither a known first day of the last menstrual period nor a regular menstrual cycle, the ultrasound estimate was used at the first antenatal visit. Pregnancy was classified into the first, second, and third trimesters using gestational age: $<14,14-27$, and $28-42$ weeks, respectively.

The follow-up of study participants throughout pregnancy is shown in Figure 1. Of 4497 participants at study entry, 3472 women were in the first trimester, 1025 women were in the second trimester. With following up, 2986 women and 2261 women were left at the end of gestational weeks 24 and 36, respectively. All eligible participants provided written informed consent, the Guangxi Medical University Institutional Review Board approved the present protocols.

\section{Data collection and laboratory measures}

The three hospitals performed the same antenatal examination, laboratory procedure, and quality control. At the first antenatal visit, baseline information on maternal age, ethnicity, education, family income, residence, gestational age, parity, and folic acid supplement was based on interview questionnaires, anthropometric measures (e.g. body weight and height) and blood pressure were recorded through physical examinations. Blood pressure readings and body weight were prospectively recorded from the first to the last antenatal visit. Blood pressure was measured with Omron HEM 907 IntelliSense professional digital blood pressure monitor (Omron Healthcare Ltd., Dalian, China) using an averaging mode in a sitting position. After at least 5 minutes of rest, an appropriately sized upper arm cuff was applied to the right arm, the mean value of two blood pressure readings with a pause of 60 seconds between each measurement was recorded.

Fasting blood was repeatedly collected at the first antenatal visit that ranged from gestational weeks 10 to 16 , around gestational weeks $20,24,32$, and 36 . All samples were performed using the standard protocol for clinical laboratory tests. $\mathrm{Hb}$ concentration value in whole blood was performed with Beckman Coulter AcT 5 Diff hematology analyzer (Beckman Coulter Inc., Fullerton, USA), and was determined via cyanmethhemoglobin method. The interassay coefficients of variation for $\mathrm{Hb}$ concentrations ranged from $3.1 \%$ to $8.9 \%$ throughout the study period. Serum total cholesterol, serum triglycerides, and plasma glucose were measured using Hitachi 7170A or 7020 full-automatic biochemical analyzer (Hitachi Ltd., Tokyo, Japan).

\section{Definitions of variables}

BMI was calculated by dividing weight in kilograms by standing height that was measured at enrollment in meters squared $\left(\mathrm{kg} / \mathrm{m}^{2}\right)$. High BMI was defined as being more than or equal to the 90th percentile cutoff of BMI. High $\mathrm{Hb}$ concentration was defined as an $\mathrm{Hb}$ level of $\geq 13.0 \mathrm{~g} / \mathrm{dL}$ [15]. Family income was the total combined family income including wages, salaries, self-employment, and the other source during the last 12 months. Urban residence was defined as urban districts, central or fringe areas of city or town with a population density higher than $1500 / \mathrm{km}^{2}$. Parity was the numbers of times woman has given birth including stillbirths. Folic acid supplement was defined as women took a daily supplement of folic acid during 3 months before pregnancy to the first antenatal visit. Diabetes mellitus was defined as a fasting glucose $\geq 126 \mathrm{mg} / \mathrm{dL}$, a non-fasting glucose $\geq 200 \mathrm{mg} / \mathrm{dL}$, or a self-report physician diagnosis, or current medication use.

\section{Statistical analysis}

With respect to the statistical analyses of $\mathrm{BMI}, \mathrm{Hb}$ concentrations, SBP, and DBP, the first measurements at study entry (gestational weeks 10 to $<14$ ) were used for the first trimester; the averages of measurements including the first antenatal visit at gestational weeks 14 to 16 , 


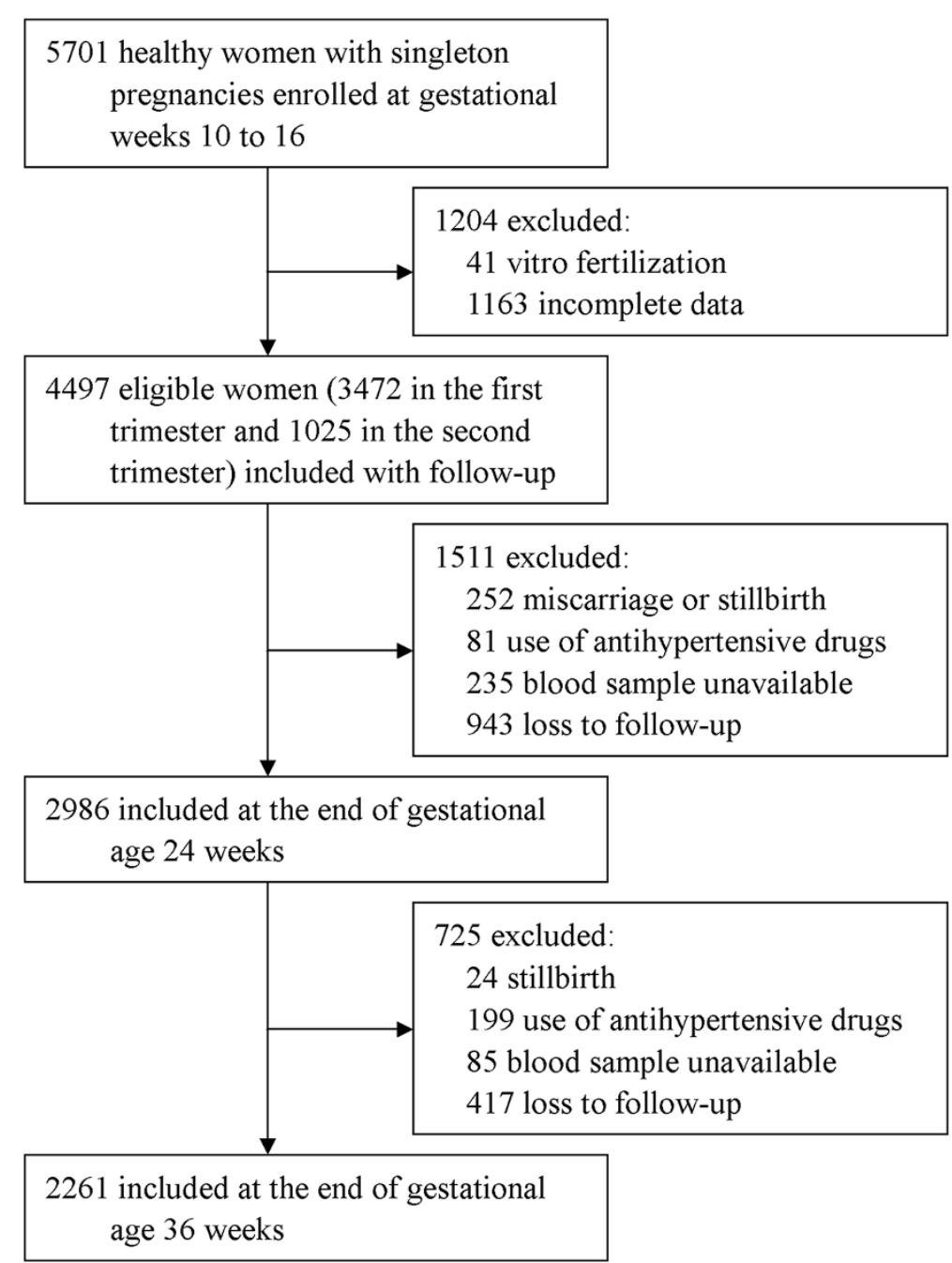

Figure 1 Flow diagram of study participants throughout pregnancy. 3472, 2986, and 2261 at each time point represent the number of women with complete data including body mass index (BMI), blood pressure, and blood samples as well as basic characteristics in the first, second and third trimesters, respectively.

around gestational weeks 20 and 24 were used for the second trimester; the averages of measurements around gestational weeks 32 and 36 were used for the third trimester. All analyses were performed using Stata, version 12 (StataCorp LP, College Station, Texas).

We fully evaluated the effects of high BMI and high $\mathrm{Hb}$ concentrations on blood pressure by trimesters of pregnancy. To do this, first, we generated two binary variables including $b m i$ (dichotomized into high BMI and non-high BMI) and $h b$ (dichotomized into high $\mathrm{Hb}$ and non-high $\mathrm{Hb}$ ), and used multivariable linear regression to calculate the differences in SBP and DBP comparing high $\mathrm{BMI}$ or high $\mathrm{Hb}$ to the non-high category, respectively. Second, we used multivariable linear regression to evaluate the differences in SBP and DBP, comparing the combined categories of high $\mathrm{BMI}$ and high $\mathrm{Hb}$, high $\mathrm{BMI}$ and non-high $\mathrm{Hb}$, non-high $\mathrm{BMI}$ and high $\mathrm{Hb}$ to non-high $\mathrm{BMI}$ and non-high $\mathrm{Hb}$, respectively. Third, using multivariable linear regression, we further assessed the interaction as departure from additivity between high $\mathrm{BMI}$ and high $\mathrm{Hb}$ on SBP and DBP by including $b m i, h b$, and the product of $b m i$ and $h b$ in models, and obtained the amount of interaction, which equaled the regression coefficient of the product term. The corresponding methodology was described by Knol et al. [16].

For multivariable regression, we fitted 3 models with progressive levels of adjustment. Model 1 was adjusted for age (continuous) and ethnicity (Han, Zhuang, other). Model 2 was further adjusted for education $(<12$ years, $\geq 12$ years), family income < US\$ 3000 (yes, no), urban residence (yes, no), parity $(0,1,>1)$, and folic acid supplement (yes, no). Model 3 was further adjusted for serum total cholesterol (continuous), serum triglycerides (continuous), and diabetes mellitus (yes, no). 


\section{Results}

The main characteristics of the study population by trimester are shown in Table 1 . On average, the mean age of women by trimester ranged from 25.2 to 26.3 years. The means of BMI, $\mathrm{Hb}$ concentrations, SBP and DBP by trimester ranged from 22.9 to $26.5 \mathrm{~kg} / \mathrm{m}^{2}, 11.7$ to $12.5 \mathrm{~g} / \mathrm{dL}, 107.0$ to $112.8 \mathrm{mmHg}$ and 66.4 to $73.8 \mathrm{mmHg}$, respectively. BMI increased progressively during pregnancy, however, $\mathrm{Hb}$ concentrations, SBP and DBP in the second trimester were lower than in the first and third trimesters.

In the first trimester, either of $\mathrm{BMI}$ and $\mathrm{Hb}$ was positively associated with both SBP and DBP $(P<0.05)$ (Figure 2$)$. In models adjusted for age and ethnicity, women with high $\mathrm{BMI}$ and high $\mathrm{Hb}$ had significantly increased differences for SBP and DBP compared to women with non-high BMI and non-high $\mathrm{Hb}$. After full adjustment, however, the differences became weak, the average difference in women with high BMI and high $\mathrm{Hb}$ compared to women with non-high BMI and non-high $\mathrm{Hb}$ were $2.9 \mathrm{mmHg}$ (95\% CI: 0.8 to $5.0 \mathrm{mmHg}$ ) in SBP, and $3.9 \mathrm{mmHg}$ (95\% CI: 1.5 to $6.3 \mathrm{mmHg}$ ) in DBP, respectively (Table 2). We found no evidence of significant interaction between high BMI and high $\mathrm{Hb}$ on SBP $(P=0.14)$ and DBP $(P=0.38)$ in full-adjusted models (Table 3$)$.

Only BMI was positively associated with SBP in the second trimester $(P<0.05)$ (Figure 2$)$. We further found significant differences in SBP comparing women with high $\mathrm{BMI}$ and high $\mathrm{Hb}$ to those with non-high $\mathrm{BMI}$ and non-high $\mathrm{Hb}$, but non-significant in DBP regardless of multivariable-adjusted models. After full adjustment, the average differences in SBP and DBP, comparing women with high $\mathrm{BMI}$ and high $\mathrm{Hb}$ to those with non-high $\mathrm{BMI}$ and non-high $\mathrm{Hb}$, were $2.6 \mathrm{mmHg}$ (95\% CI: 0.4 to
$4.8 \mathrm{mmHg}$ ) and $1.5 \mathrm{mmHg}$ (95\% CI: -1.3 to $4.3 \mathrm{mmHg}$ ), respectively (Table 4). Also, there was no evidence of significant interaction between high $\mathrm{BMI}$ and high $\mathrm{Hb}$ on SBP $(P=0.3)$ or DBP $(P=0.11)$ in full-adjusted model (Table 3).

In the third trimester, BMI was positively with both SBP and DBP, but higher $\mathrm{Hb}$ was only associated with higher DBP $(P<0.05)$ (Figure 2$)$. After adjustment for age and ethnicity, there were significant increases in the differences for SBP and DBP compared to women with non-high $\mathrm{BMI}$ and non-high $\mathrm{Hb}$. Full adjustment for confounding did not materially affect this association, the average differences in SBP and DBP, comparing women with high $\mathrm{BMI}$ and high $\mathrm{Hb}$ to those with nonhigh BMI and non-high $\mathrm{Hb}$, were $4.8 \mathrm{mmHg}$ (95\% CI: 2.3 to $7.4 \mathrm{mmHg}$ ) and $5.7 \mathrm{mmHg}$ (95\% CI: 3.2 to $8.3 \mathrm{mmHg}$ ), respectively (Table 5). For the interaction, we found significant synergistic effects between high $\mathrm{BMI}$ and high $\mathrm{Hb}$ on $\operatorname{SBP}(P=0.02)$ and $\operatorname{DBP}(P=0.004)$ in full-adjusted models, the amount of interaction on SBP and DBP were $2.0 \mathrm{mmHg}$ (95\% CI: 0.1 to $3.9 \mathrm{mmHg}$ ) and $2.3 \mathrm{mmHg}$ (95\% CI: 0.4 to $4.3 \mathrm{mmHg}$ ), respectively (Table 3 ).

\section{Discussion}

In this study, differences in the associations of BMI and $\mathrm{Hb}$ with either SBP or DBP were present throughout pregnancy. BMI was positively associated with SBP across 3 trimesters, but with DBP in the first and third trimesters; higher $\mathrm{Hb}$ concentrations were associated with increased SBP only in the first trimester, but with increased DBP in the first and third trimesters. Furthermore, we found significant interaction between high BMI and high $\mathrm{Hb}$ on elevated both SBP and DBP only in the third trimester.

Table 1 Baseline characteristics of the study population by trimesters of pregnancy ${ }^{\dagger}$

\begin{tabular}{llll}
\hline Characteristic & $\mathbf{1}^{\text {st }}$ trimester $(\mathbf{N}=\mathbf{3 4 7 2})$ & $\mathbf{2}^{\text {nd }}$ trimester $(\mathbf{N}=\mathbf{2 9 8 6})$ & $\mathbf{3}^{\text {rd }}$ trimester $(\mathbf{N}=\mathbf{2 2 6 1})$ \\
\hline Maternal age, year & $26.0(0.8)$ & $26.3(0.5)$ & $25.2(0.6)$ \\
The Han, $\mathrm{n}(\%)$ & $2226(64.1)$ & $1965(65.8)$ & $1526(67.5)$ \\
Education $(\geq 12$ years), $\mathrm{n}(\%)$ & $1476(42.5)$ & $1170(39.2)$ & $1011(44.7)$ \\
Family income $(<\$ 3000), \mathrm{n}(\%)$ & $736(21.2)$ & $582(19.5)$ & $355(15.7)$ \\
Urban residence, $\mathrm{n}(\%)$ & $1628(46.9)$ & $1582(53.0)$ & $1302(57.6)$ \\
Parity (nulliparous), $\mathrm{n}(\%)$ & $2170(62.5)$ & $1765(59.1)$ & $1490(65.9)$ \\
Folic acid supplement, $\mathrm{n}(\%)$ & $1430(41.2)$ & $1135(38.0)$ & $988(43.7)$ \\
Serum total cholesterol, $\mathrm{mg} / \mathrm{dL}$ & $181.6(1.1)$ & $221.5(0.7)$ & $243.6(0.8)$ \\
Serum triglyceride, $\mathrm{mg} / \mathrm{dL}$ & $124.9(0.9)$ & $177.1(1.1)$ & $256.8(1.3)$ \\
Diabetes mellitus, $\mathrm{n}(\%)$ & $69(2.0)$ & $66(2.2)$ & $133(5.9)$ \\
Body mass index, $\mathrm{kg} / \mathrm{m}^{2}$ & $22.9(0.2)$ & $24.1(0.2)$ & $26.5(0.3)$ \\
Hemoglobin, $\mathrm{g} / \mathrm{dL}$ & $12.5(0.2)$ & $11.7(0.1)$ & $11.8(0.1)$ \\
Systolic blood pressure, $\mathrm{mmHg}$ & $110.5(1.3)$ & $107.0(1.1)$ & $112.8(1.0)$ \\
Diastolic blood pressure, $\mathrm{mmHg}$ & $68.4(0.6)$ & $66.4(0.5)$ & $73.8(0.7)$ \\
\hline
\end{tabular}

${ }^{\dagger}$ Values are means (standard error) or number (percentage) unless otherwise noted. 


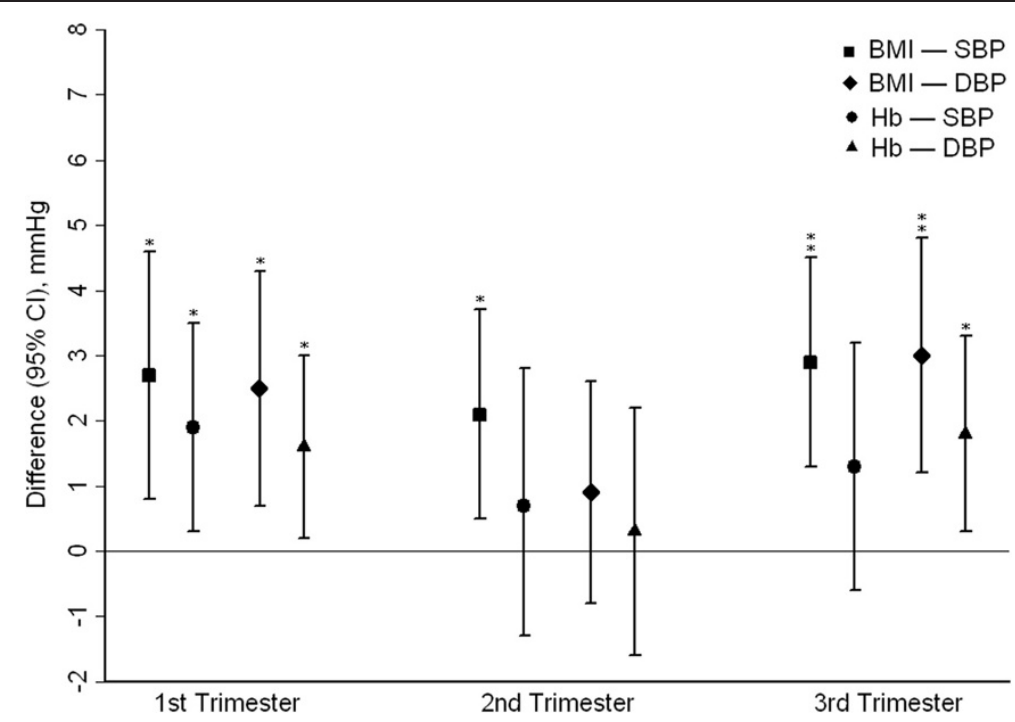

Figure 2 Differences (95\% Cls) in SBP and DBP with BMI and $\mathrm{Hb}$ by trimesters of pregnancy. Differences were adjusted for age (continuous), ethnicity (Han, Zhuang, other), education ( $<12$ years, $\geq 12$ years), family income < US 3000 (yes, no), urban residence (yes, no), parity $(0,1,>1)$, folic acid supplement (yes, no), total cholesterol (continuous), triglycerides (continuous), and diabetes mellitus (yes, no). Comparing the high to the non-high categories: ${ }^{*} P<0.05,{ }^{* *} P<0.001$.

Some observational studies have consistently shown a positive association between maternal BMI and blood pressure, whether in pregnancy [3-6] or prepregnancy [17-20], although these associations were concluded by different statistical models. A recent system review including 13 trials, however, indicates that dietary intervention appears effective to reduce total and weekly gestational weight gain, but no significant effect on preventing preeclampsia and gestational diabetes [21]. For $\mathrm{Hb}$, several observational studies found significantly increased $\mathrm{Hb}$ concentrations in women who developed PIH in the second or third trimester [7-9]. Also, a recent study showed that $\mathrm{Hb}$ level was positively associated with both SBP and DBP in a large cohort of healthy individuals [22]. In our analysis, we excluded women with PIH or preeclampsia mainly owing to antihypertensive medication, in contrast to previous research that defined outcome as PIH or preeclampsia, our study thus focused on the physiological effects of BMI and $\mathrm{Hb}$ on blood pressure in the whole range of trimesters of pregnancy. As a whole, our finding regarding the positive associations of $\mathrm{BMI}$ and $\mathrm{Hb}$ with blood pressure supports previous research.

The mechanisms for increased BMI or $\mathrm{Hb}$ concentrations with elevated blood pressure in pregnancy have been

Table 2 Difference $(95 \% \mathrm{Cl})$ in blood pressure by categories of BMI and $\mathrm{Hb}$ levels in first trimester

\begin{tabular}{|c|c|c|c|c|}
\hline & \multicolumn{2}{|c|}{ Non-high BMI $\left(<26.8 \mathrm{~kg} / \mathrm{m}^{2}\right)$} & \multicolumn{2}{|c|}{ High BMI $\left(\geq 26.8 \mathrm{~kg} / \mathrm{m}^{2}\right)$} \\
\hline & $\mathrm{Hb}<13.0 \mathrm{~g} / \mathrm{dL}$ & $\mathrm{Hb} \geq 13.0 \mathrm{~g} / \mathrm{dL}$ & $\mathrm{Hb}<13.0 \mathrm{~g} / \mathrm{dL}$ & $\mathrm{Hb} \geq 13.0 \mathrm{~g} / \mathrm{dL}$ \\
\hline Number & 2218 & 907 & 213 & 134 \\
\hline $\mathrm{SBP}(\mathrm{mmHg})^{\mathrm{a}}$ & 109.7 & 111.7 & 112.4 & 113.3 \\
\hline Model $1^{\mathrm{b}}$ & 0.0 (reference) & $2.6(0.9,4.2)$ & $3.0(0.5,5.5)$ & $4.0(2.1,6.0)$ \\
\hline Model $2^{c}$ & 0.0 (reference) & $2.5(0.8,4.2)$ & $2.9(0.5,5.3)$ & $3.8(1.7,5.4)$ \\
\hline Model $3^{d}$ & 0.0 (reference) & $1.4(-0.3,3.1)$ & $2.6(0.3,4.9)$ & $2.9(0.8,5.0)$ \\
\hline $\mathrm{DBP}(\mathrm{mmHg})^{\mathrm{a}}$ & 67.5 & 69.0 & 70.0 & 72.4 \\
\hline Model $1^{b}$ & 0.0 (reference) & $1.9(-0.3,4.2)$ & $3.2(0.6,5.7)$ & $5.1(2.7,7.6)$ \\
\hline Model $2^{c}$ & 0.0 (reference) & $1.9(-0.2,4.1)$ & $3.2(0.8,5.6)$ & $5.0(2.7,7.4)$ \\
\hline Model $3^{d}$ & 0.0 (reference) & $1.0(-1.0,3.0)$ & $2.5(0.1,4.9)$ & $3.9(1.5,6.3)$ \\
\hline
\end{tabular}

$\mathrm{Cl}$, confidence interval; SBP, systolic blood pressure; DBP, diastolic blood pressure; $\mathrm{Hb}$, Hemoglobin.

${ }^{a}$ Mean SBP; mean DBP.

${ }^{\mathrm{b}}$ Model 1: Adjusted for age (continuous) and ethnicity (Han, Zhuang, other).

'Model 2: Further adjusted for education ( $<12$ years, $\geq 12$ years), family income $<$ US\$ 3000 (yes, no), urban residence (yes, no), parity ( $0,1,>1)$, and folic acid supplement (yes, no).

${ }^{\mathrm{d}}$ Model 3: Further adjusted for total cholesterol (continuous), triglycerides (continuous), and diabetes mellitus (yes, no). 


\begin{tabular}{|c|c|c|c|c|}
\hline \multirow[t]{2}{*}{ Variable } & \multicolumn{2}{|l|}{ SBP } & \multicolumn{2}{|l|}{ DBP } \\
\hline & $\beta(95 \% \mathrm{Cl})$ & $P$ value & $\beta(95 \% \mathrm{Cl})$ & $P$ value \\
\hline \multicolumn{5}{|c|}{ First trimester } \\
\hline Constant & $70.3(64.0,76.6)$ & $<0.001$ & $55.6(47.9,63.3)$ & $<0.001$ \\
\hline bmi & $2.6(0.3,4.9)$ & 0.01 & $2.5(0.1,4.9)$ & 0.03 \\
\hline$h b$ & $1.4(-0.3,3.1)$ & 0.09 & $1.0(-1.0,3.0)$ & 0.16 \\
\hline$b m i \times h b$ & $-1.1(-3.7,1.6)$ & 0.14 & $0.4(-2.3,3.1)$ & 0.38 \\
\hline \multicolumn{5}{|c|}{ Second trimester } \\
\hline Constant & $72.1(65.8,78.4)$ & $<0.001$ & $56.9(49.1,64.7)$ & $<0.001$ \\
\hline$b m i$ & $1.9(-0.5,4.3)$ & 0.22 & $0.8(-1.5,3.2)$ & 0.32 \\
\hline$h b$ & $0.6(-1.6,2.8)$ & 0.54 & $-0.2(-2.3,1.9)$ & 0.63 \\
\hline$b m i \times h b$ & $0.1(-2.6,2.8)$ & 0.30 & $0.9(-1.7,3.5)$ & 0.11 \\
\hline \multicolumn{5}{|c|}{ Third trimester } \\
\hline Constant & $74.1(67.8,80.4)$ & $<0.001$ & $59.3(51.6,67.0)$ & $<0.001$ \\
\hline bmi & $2.0(0.3,3.7)$ & 0.009 & $2.2(0.2,4.2)$ & 0.01 \\
\hline$h b$ & $0.8(-1.1,2.7)$ & 0.27 & $1.2(-1.0,3.4)$ & 0.12 \\
\hline$b m i \times h b$ & $2.0(0.1,3.9)$ & 0.02 & $2.3(0.4,4.3)$ & 0.004 \\
\hline
\end{tabular}

${ }^{\dagger}$ Adjusted for age (continuous), ethnicity (Han, Zhuang, other), education $(<12$ years, $\geq 12$ years), family income $<$ US $\$ 3000$ (yes, no), urban residence (yes, no), parity $(0,1,>1)$, folic acid supplement (yes, no), total cholesterol (continuous), triglycerides (continuous), and diabetes mellitus (yes, no).

postulated. For maternal BMI, the associations of gestational adiposity with dyslipidaemia, hyperglycaemia, and insulin resistance are well recognized [4,23-25]. These risk patterns lead to oxidative stress and lipoprotein oxidation contributing to endothelial dysfunction [26] that is characterized by the pathogenesis of preeclampsia [27]. Additionally, several functional changes associated with maternal obesity, including lipid alternations, sleep apnea, and increased cardiac output and oxygen consumption, are involved in hypertensive disorders in pregnancy [28-30]. For $\mathrm{Hb}$, the mechanisms that contribute to hypertensive disorders of pregnancy may be related with blood viscosity, which can be induced by elevation of hematocrit and $\mathrm{Hb}$ levels, since it has been suggested that increased blood viscosity may worsen cardiovascular function partly through an effect on blood pressure [31]. Given this finding regarding blood viscosity, it might probably explain the previous studies [7-9] that the positive associations between increased $\mathrm{Hb}$ and $\mathrm{PIH}$ were in agreement with elevated blood viscosity during pregnancy. Furthermore, free $\mathrm{Hb}$ is a scavenger of nitric oxide (NO), which can relax the muscle cells, increased free $\mathrm{Hb}$ levels may thus bind to $\mathrm{NO}$ and contribute to vasoconstriction and hypertension [32,33]. With so many potential mechanisms involved, perhaps it is not surprised by the differences in the associations of $\mathrm{BMI}$ and $\mathrm{Hb}$ concentrations with SBP or DBP throughout pregnancy.

This is the first analysis to our knowledge of the potential interaction between high $\mathrm{BMI}$ and high $\mathrm{Hb}$ concentrations on blood pressure in pregnancy. Our main finding is that both SBP and DBP are significantly elevated in women with high BMI and high $\mathrm{Hb}$ in the third trimester of pregnancy, and the interaction between high BMI and high $\mathrm{Hb}$ indicates a synergistic effect on blood pressure. In contrast to the second trimester, both high $\mathrm{BMI}$ and high $\mathrm{Hb}$ were more likely to raise higher blood pressure in the first and third trimesters, however, further comparison with the first trimester, blood pressure elevated by the individual effect of high BMI or high $\mathrm{Hb}$ was consistent in the third trimester. Therefore, this suggests that the interaction in the third trimester, may not only depend on the excess amounts in blood pressure raised by high levels of $\mathrm{BMI}$ and $\mathrm{Hb}$, but also the

Table 4 Difference $(95 \% \mathrm{Cl})$ in blood pressure by categories of $\mathrm{BMI}$ and $\mathrm{Hb}$ levels in second trimester

\begin{tabular}{|c|c|c|c|c|}
\hline & \multicolumn{2}{|c|}{ Non-high BMI $\left(<28.5 \mathrm{~kg} / \mathrm{m}^{2}\right)$} & \multicolumn{2}{|c|}{ High BMI $\left(\geq 28.5 \mathrm{~kg} / \mathrm{m}^{2}\right)$} \\
\hline & $\mathrm{Hb}<13.0 \mathrm{~g} / \mathrm{dL}$ & $\mathrm{Hb} \geq 13.0 \mathrm{~g} / \mathrm{dL}$ & $\mathrm{Hb}<13.0 \mathrm{~g} / \mathrm{dL}$ & $\mathrm{Hb} \geq 13.0 \mathrm{~g} / \mathrm{dL}$ \\
\hline Number & 2201 & 488 & 190 & 109 \\
\hline $\mathrm{SBP}(\mathrm{mmHg})^{\mathrm{a}}$ & 106.3 & 107.7 & 108.6 & 108.9 \\
\hline Model $1^{\mathrm{b}}$ & 0.0 (reference) & $1.1(-1.3,3.4)$ & $2.2(-0.6,5.0)$ & $3.2(1.0,5.5)$ \\
\hline Model $2^{c}$ & 0.0 (reference) & $0.9(-1.5,3.3)$ & $2.1(-0.4,4.6)$ & $3.0(0.9,5.1)$ \\
\hline Model $3^{d}$ & 0.0 (reference) & $0.6(-1.6,2.8)$ & $1.9(-0.5,4.3)$ & $2.6(0.4,4.8)$ \\
\hline $\mathrm{DBP}(\mathrm{mmHg})^{\mathrm{a}}$ & 66.2 & 66.4 & 67.2 & 68.1 \\
\hline Model $1^{\mathrm{b}}$ & 0.0 (reference) & $0.5(-1.9,2.8)$ & $1.4(-1.0,3.8)$ & $2.2(-0.8,5.2)$ \\
\hline Model $2^{c}$ & 0.0 (reference) & $0.2(-2.0,2.5)$ & $1.2(-1.1,3.7)$ & $2.2(-0.7,5.1)$ \\
\hline Model $3^{d}$ & 0.0 (reference) & $-0.2(-2.3,1.9)$ & $0.8(-1.5,3.2)$ & $1.5(-1.3,4.3)$ \\
\hline
\end{tabular}

$\mathrm{Cl}$, confidence interval; SBP, systolic blood pressure; $\mathrm{DBP}$, diastolic blood pressure; $\mathrm{Hb}$, Hemoglobin.

${ }^{a}$ Mean SBP; mean DBP.

${ }^{\mathrm{b}}$ Model 1: Adjusted for age (continuous) and ethnicity (Han, Zhuang, other).

${ }^{c}$ Model 2: Further adjusted for education ( $<12$ years, $\geq 12$ years), family income $<$ US\$ 3000 (yes, no), urban residence (yes, no), parity ( $\left.0,1,>1\right)$, and folic acid supplement (yes, no).

${ }^{\mathrm{d}}$ Model 3: Further adjusted for total cholesterol (continuous), triglycerides (continuous), and diabetes mellitus (yes, no). 
Table 5 Difference $(95 \% \mathrm{Cl})$ in blood pressure by categories of $\mathrm{BMI}$ and $\mathrm{Hb}$ levels in third trimester

\begin{tabular}{|c|c|c|c|c|}
\hline & \multicolumn{2}{|c|}{ Non-high BMI $(<30.9$ kg/m²) } & \multicolumn{2}{|c|}{ High BMI $\left(\geq 30.9 \mathrm{~kg} / \mathrm{m}^{2}\right)$} \\
\hline & $\mathrm{Hb}<13.0 \mathrm{~g} / \mathrm{dL}$ & $\mathrm{Hb} \geq 13.0 \mathrm{~g} / \mathrm{dL}$ & $\mathrm{Hb}<13.0 \mathrm{~g} / \mathrm{dL}$ & $\mathrm{Hb} \geq 13.0 \mathrm{~g} / \mathrm{dL}$ \\
\hline Number & 1435 & 600 & 148 & 78 \\
\hline $\mathrm{SBP}(\mathrm{mmHg})^{\mathrm{a}}$ & 111.3 & 112.5 & 113.6 & 116.9 \\
\hline Model $1^{b}$ & 0.0 (reference) & $1.3(-1.0,3.7)$ & $2.2(0.3,4.1)$ & $5.8(3.2,8.4)$ \\
\hline Model $2^{c}$ & 0.0 (reference) & $1.2(-1.0,3.4)$ & $2.2(0.2,4.1)$ & $5.6(3.1,8.1)$ \\
\hline Model $3^{d}$ & 0.0 (reference) & $0.8(-1.1,2.7)$ & $2.0(0.3,3.7)$ & $4.8(2.3,7.4)$ \\
\hline $\mathrm{DBP}(\mathrm{mmHg})^{a}$ & 72.5 & 74.0 & 74.8 & 78.5 \\
\hline Model $1^{b}$ & 0.0 (reference) & $1.9(-0.6,4.3)$ & $2.5(0.4,4.7)$ & $6.5(3.8,9.1)$ \\
\hline Model $2^{c}$ & 0.0 (reference) & $1.7(-0.5,3.9)$ & $2.4(0.3,4.5)$ & $6.2(3.6,8.8)$ \\
\hline Model $3^{d}$ & 0.0 (reference) & $1.2(-1.0,3.4)$ & $2.2(0.2,4.2)$ & $5.7(3.2,8.3)$ \\
\hline
\end{tabular}

$\mathrm{Cl}$, confidence interval; SBP, systolic blood pressure; DBP, diastolic blood pressure; $\mathrm{Hb}$, Hemoglobin.

${ }^{a}$ Mean SBP; mean DBP.

${ }^{\mathrm{b}}$ Model 1: Adjusted for age (continuous) and ethnicity (Han, Zhuang, other).

${ }^{c}$ Model 2: Further adjusted for education ( $<12$ years, $\geq 12$ years), family income $<$ US\$ 3000 (yes, no), urban residence (yes, no), parity ( $\left.0,1,>1\right)$, and folic acid supplement (yes, no).

${ }^{\mathrm{d}}$ Model 3: Further adjusted for total cholesterol (continuous), triglycerides (continuous), and diabetes mellitus (yes, no).

physiological changes in pregnancy. In the present analysis, even although the synergistic effects on SBP and DBP increased only $2 \mathrm{mmHg}$ and $2.3 \mathrm{mmHg}$, respectively, perhaps we cannot rule out the possible adverse effects on pregnancy outcomes. Randomized controlled trial data have shown that lowering SBP of $3 \mathrm{mmHg}$ may result in a $16 \%$ reduction of cardiovascular events and a $22 \%$ reduction of fatal and nonfatal strokes [34]. For pregnant women, the biological effect of interaction on increased blood pressure, even with small scale, thus needs to be confirmed in further studies. Moreover, the tendency of blood pressure in women with high BMI and high $\mathrm{Hb}$ concentrations may need to be monitored with care during the antenatal visit.

The mechanisms underlying the interaction between high $\mathrm{BMI}$ and high $\mathrm{Hb}$ on increased blood pressure are unclear. Based on the association of elevated blood viscosity with adiposity or increased $\mathrm{Hb}$ levels [7,10-13], the present study partly supports our hypothesis that high BMI and high $\mathrm{Hb}$ may have a combined effect on increased blood pressure via elevated blood viscosity during normal pregnancy. However, we do not have a good explanation on mechanism for the interaction in the third trimester, but not in the first and second trimesters. Generally in normal pregnancy, blood volume, stroke volume, and cardiac output increase progressively from the first trimester until term [35], whereas blood viscosity has a drop until 29 weeks gestation, followed by a small increase toward term [36]. In our study, we cannot determine the change in hemodynamics owing to lack of measuring blood viscosity using viscometer, further studies thus need to systematically evaluate the role of blood viscosity in the associations of increased BMI and $\mathrm{Hb}$ concentrations with blood pressure in pregnancy.
The present study has some limitations. First, owing to our cross-sectional analysis, we cannot determine the causality between increased BMI or $\mathrm{Hb}$ concentrations and elevated blood pressure. Second, the physiological adaptations in maternal BMI, Hb concentrations, and blood pressure are dynamic throughout pregnancy. We cannot collect blood samples at every antenatal visit due to the schedule in routine antenatal care, hence this probably weakened the representation of 3 trimesters of pregnancy only using the measurement at study entry, around gestational weeks 20 and 24, 32 and 36. Third, we accumulatively lost 943 (21\%) and 417 (14\%) participants with the follow-up in two subsequent trimesters, respectively. Based on our analysis, the characteristics of participants lost to follow up were not significantly different with participants who remained in follow up except for family income and urban residence. Moreover, the regression coefficients in each trimester did not significantly change after adjustment for the two variables, our results thus did not substantially be influenced by loss to follow up.

\section{Conclusions}

$\mathrm{BMI}$ and $\mathrm{Hb}$ concentrations appear to have different associations with blood pressure throughout pregnancy. Even more important, our findings indicate a synergistic effect between high BMI and high $\mathrm{Hb}$ on blood pressure in the third trimester of pregnancy. Further prospective research is needed to identify the biological mechanism of interaction, and evaluate its clinical role in pregnancy.

Competing interests

The authors declare that they have no competing interests. 


\section{Authors' contributions}

QZ, JX and XQ designed the research and wrote the manuscript. QZ and YD analyzed the data. YL contributed in the program development and participated in the program protocol. $\mathrm{JH}$ and $\mathrm{XL}$ collaborated in the data interpretation and assisted in data analysis. All authors reviewed and edited manuscript. The final manuscript was read and approved by all authors.

\section{Acknowledgments}

We thank all the pregnant women for participating in this study. This research was supported by Natural Science Foundation of China (NSFC) grant 81360422

\section{Author details \\ 'Department of Epidemiology, Guangxi Medical University School of Public Health, 22 Shuangyong Road, Nanning, Guangxi 530021, China. ${ }^{2}$ Department of Pediatrics, Nanning Maternal and Child Health Hospital, Nanning, China. ${ }^{3}$ Department of Comprehensive Laboratory, Guigang Entry-Exit Inspection and Quarantine Bureau, Guigang, China.}

Received: 14 May 2013 Accepted: 6 May 2014

Published: 20 May 2014

\section{References}

1. Langenveld J, Jansen S, van der Post J, Wolf H, Mol BW, Ganzevoort W: Recurrence risk of a delivery before 34 weeks of pregnancy due to an early onset hypertensive disorder: a systematic review. Am J Perinatol 2010, 27(7):565-571.

2. Khan KS, Wojdyla D, Say L, Gulmezoglu AM, Van Look PF: WHO analysis of causes of maternal death: a systematic review. Lancet 2006, 367 (9516):1066-1074.

3. Leeners B, Rath W, Kuse S, Irawan C, Imthurn B, Neumaier-Wagner P: BMI: new aspects of a classical risk factor for hypertensive disorders in pregnancy. Clin Sci (Lond) 2006, 111(1):81-86.

4. Ramsay JE, Ferrell WR, Crawford L, Wallace AM, Greer IA, Sattar N: Maternal obesity is associated with dysregulation of metabolic, vascular, and inflammatory pathways. J Clin Endocrinol Metab 2002, 87(9):4231-4237.

5. Mahomed K, Williams MA, Woelk GB, Jenkins-Woelk L, Mudzamiri S, Longstaff $L$, Sorensen TK: Risk factors for pre-eclampsia among Zimbabwean women: maternal arm circumference and other anthropometric measures of obesity. Paediatr Perinat Epidemiol 1998, 12(3):253-262.

6. Group HSCR: Hyperglycaemia and Adverse Pregnancy Outcome (HAPO) Study: associations with maternal body mass index. BJOG 2010, 117(5):575-584.

7. Knottnerus JA, Delgado LR, Knipschild PG, Essed GG, Smits F: Haematologic parameters and pregnancy outcome: A prospective cohort study in the third trimester. J Clin Epidemiol 1990, 43(5):461-466.

8. Huisman A, Aarnoudse JG: Increased 2nd trimester hemoglobin concentration in pregnancies later complicated by hypertension and growth retardation: early evidence of a reduced plasma volume. Acta Obstet Gynecol Scand 1986, 65(6):605-608.

9. Rasmussen S, Oian P: Smoking, hemoglobin concentration and pregnancyinduced hypertension. Gynecol Obstet Invest 1998, 46(4):225-231.

10. Yip R: Significance of an abnormally low or high hemoglobin concentration during pregnancy: special consideration of iron nutrition Am J Clin Nutr 2000, 72(1 Suppl):272S-279S.

11. Murphy JF, O'Riordan J, Newcombe RG, Coles EC, Pearson JF: Relation of haemoglobin levels in first and second trimesters to outcome of pregnancy. Lancet 1986, 1(8488):992-995.

12. Gobel BO, Schulte-Gobel A, Weisser B, Glanzer K, Vetter H, Dusing R: Arterial blood pressure. Correlation with erythrocyte count, hematocrit, and hemoglobin concentration. Am J Hypertens 1991, 4(1 Pt 1):14-19.

13. Brun JF, Varlet-Marie E, Raynaud de Mauverger E, Mercier J: Both overall adiposity and abdominal adiposity increase blood viscosity by separate mechanisms. Clin Hemorheol Microcirc 2011, 48(4):257-263.

14. Rasmussen S, Bergsjo P, Jacobsen G, Haram K, Bakketeig LS: Haemoglobin and serum ferritin in pregnancy-correlation with smoking and body mass index. Eur J Obstet Gynecol Reprod Biol 2005, 123(1):27-34.

15. Laflamme EM: Maternal hemoglobin concentration and pregnancy outcome: a study of the effects of elevation in el alto, bolivia. Mcgill J Med 2011, 13(1):47.
16. Knol MJ, van der Tweel I, Grobbee DE, Numans ME, Geerlings MI: Estimating interaction on an additive scale between continuous determinants in a logistic regression model. Int J Epidemiol 2007, 36(5):1111-1118.

17. Hrazdilova O, Unzeitig V, Znojil V, Izakovicova-Holla L, Janku P, Vasku A Relationship of age and the body mass index to selected hypertensive complications in pregnancy. Int J Gynaecol Obstet 2001, 75(2):165-169.

18. O'Brien TE, Ray JG, Chan WS: Maternal body mass index and the risk of preeclampsia: a systematic overview. Epidemiology 2003, 14(3):368-374

19. Ehrenthal DB, Jurkovitz C, Hoffman M, Jiang X, Weintraub WS: Prepregnancy body mass index as an independent risk factor for pregnancy-induced hypertension. J Womens Health (Larchmt) 2011, 20(1):67-72.

20. Stuebe AM, Landon MB, Lai Y, Spong CY, Carpenter MW, Ramin SM, Casey B, Wapner RJ, Varner MW, Rouse DJ, Sciscione A, Catalano P, Harper M, Saade G, Sorokin Y, Peaceman AM, Tolosa JE, Eunice Kennedy Shriver National Institute of Child Health and Human Development Maternal-Fetal Medicine Units Network, Bethesda, MD: Maternal BMI, glucose tolerance, and adverse pregnancy outcomes. Am J Obstet Gynecol 2012, 207(1):62. e1-7.

21. Tanentsapf I, Heitmann BL, Adegboye AR: Systematic review of clinical trials on dietary interventions to prevent excessive weight gain during pregnancy among normal weight, overweight and obese women. BMC Pregnancy Childbirth 2011, 11:81.

22. Atsma F, Veldhuizen I, de Kort W, van Kraaij M, Pasker-de Jong P, Deinum J: Hemoglobin level is positively associated with blood pressure in a large cohort of healthy individuals. Hypertension 2012, 60(4):936-941.

23. Green JR, Pawson IG, Schumacher LB, Perry J, Kretchmer N: Glucose tolerance in pregnancy: ethnic variation and influence of body habitus. Am J Obstet Gynecol 1990, 163(1 Pt 1):86-92.

24. Challier JC, Basu S, Bintein T, Minium J, Hotmire K, Catalano PM, Hauguel-de Mouzon S: Obesity in pregnancy stimulates macrophage accumulation and inflammation in the placenta. Placenta 2008, 29(3):274-281.

25. Norman JE, Reynolds RM: The consequences of obesity and excess weight gain in pregnancy. Proc Nutr Soc 2011, 70(4):450-456.

26. D'Archivio M, Annuzzi G, Vari R, Filesi C, Giacco R, Scazzocchio B, Santangelo C, Giovannini C, Rivellese AA, Masella R: Predominant role of obesity/insulin resistance in oxidative stress development. Eur J Clin Invest 2012, 42(1):70-78.

27. Sibai B, Dekker G, Kupferminc M: Pre-eclampsia. Lancet 2005, 365(9461):785-799.

28. Murai JT, Muzykanskiy E, Taylor RN: Maternal and fetal modulators of lipid metabolism correlate with the development of preeclampsia. Metabolism 1997, 46(8):963-967.

29. Berger HA, Somers VK, Phillips BG: Sleep disordered breathing and hypertension. Curr Opin Pulm Med 2001, 7(6):386-390.

30. Stone JL, Lockwood CJ, Berkowitz GS, Alvarez M, Lapinski R, Berkowitz RL: Risk factors for severe preeclampsia. Obstet Gynecol 1994, 83(3):357-361.

31. Lowe GD, Lee AJ, Rumley A, Price JF, Fowkes FG: Blood viscosity and risk of cardiovascular events: the Edinburgh Artery Study. Br J Haematol 1997, 96(1):168-173

32. Olsson MG, Centlow M, Rutardottir S, Stenfors I, Larsson J, Hosseini-Maaf B, Olsson ML, Hansson SR, Akerstrom B: Increased levels of cell-free hemoglobin, oxidation markers, and the antioxidative heme scavenger alpha(1)microglobulin in preeclampsia. Free Radic Biol Med 2010, 48(2):284-291.

33. Cabrales P, Han G, Nacharaju P, Friedman AJ, Friedman JM: Reversal of hemoglobin-induced vasoconstriction with sustained release of nitric oxide. Am J Physiol Heart Circ Physiol 2011, 300(1):H49-H56.

34. Staessen JA, Birkenhager $\mathrm{WH}$ : Evidence that new antihypertensives are superior to older drugs. Lancet 2005, 366(9489):869-871.

35. Ouzounian JG, Elkayam U: Physiologic changes during normal pregnancy and delivery. Cardio/ Clin 2012, 30(3):317-329.

36. Huisman A, Aarnoudse JG, Heuvelmans JH, Goslinga H, Fidler V, Huisjes HJ, Zijlstra WG: Whole blood viscosity during normal pregnancy. Br J Obstet Gynaecol 1987, 94(12):1143-1149.

doi:10.1186/1471-2458-14-474

Cite this article as: Zhong et al.: Interaction of body mass index and hemoglobin concentration on blood pressure among pregnant women in Guangxi, China. BMC Public Health 2014 14:474. 